\title{
Successful use of tPA for thrombolysis in COVID related ARDS: a case series
}

\author{
Abhishek Goyal $^{1} \cdot$ Saurabh Saigal ${ }^{2} \cdot$ Yogesh Niwariya $^{3} \cdot$ Jaiprakash Sharma $^{2} \cdot$ Pooja Singh $^{2}$
}

Published online: 2 July 2020

(c) Springer Science+Business Media, LLC, part of Springer Nature 2020

\begin{abstract}
We describe successful usage of low dose Tissue plasminogen activator (tPA) (30-50 mg) in three COVID19 critically ill patients, who were in worsening respiratory failure in-spite of being on therapeutic anticoagulation. All patients had respiratory rate $>40 ; \mathrm{FiO}_{2}>0.7$ (on NIV) $\mathrm{PiO}_{2} / \mathrm{FiO}_{2}$ ratio $<100$ and D-dimer $>1000 \mathrm{ng} / \mathrm{ml}$. C.T. Pulmonary Angiography could not be done in these patients due to poor general condition, but 2D echo was normal and none of the patients was in shock. So there was no conventional indication of thrombolysis in these patients, yet after thrombolysis, we saw dramatic changes in oxygenation. All patients became off oxygen within 3-7 days and were discharged within 2 weeks. The whole idea was to prevent intubation, since mortality rates are very high in intubated COVID19 patients. tPA is associated with $<1 \%$ risk of fatal bleed. In this unprecedented pandemic with high mortality rates, thrombolysis could be an effective and safe option in carefully selected critically ill patients of COVID19.
\end{abstract}

Keywords Thrombolysis · COVID19 · Acute respiratory distress syndrome (ARDS) · Coagulopathy · Tissue plasminogen activator (tPA)

\section{Highlights}

- COVID19 related coagulopathy can cause extensive pulmonary micro thrombosis leading to ARDS and is one of the most important reasons for mortality.

- We report three cases of COVID-19 disease who were in severe ARDS $\left(\mathrm{PiO}_{2} / \mathrm{FiO}_{2}\right.$ ratio < 100) and were on the verge of intubation.

- Although no evidence of PTE was present on 2D echo, thrombolysis was done with low dose tPA; all patients had significant improvement and became off oxygen within 3-7 days.

Abhishek Goyal and Saurabh Saigal contributed equally to this work.

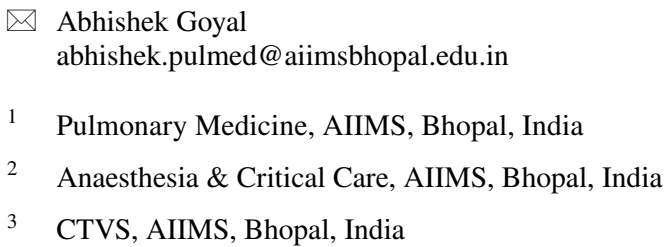

- Thrombolysis could be an effective and safe option in carefully selected critically ill patients of COVID19 ARDS and can prevent mortality.

\section{Introduction}

COVID-19 is associated with hyperinflammatory state which causes activation of coagulation cascade, causing micro or macro thrombi in various organs [1]. Significant correlation has been shown between disease severity and markers of coagulation abnormality like raised D-dimer and fibrinogen levels. Using therapeutic anticoagulation is advocated for management of COVID19 [2].

Here we present three cases of COVID-19 related severe ARDS $\left(\mathrm{PaO} 2 / \mathrm{FiO}_{2}<100\right)$. In all patients, Chest X-Ray showed diffuse bilateral peripheral infiltrates and nasopharyngeal swab was positive for COVID19. These patients were rapidly deteriorating and intubation was imminent. In all three patients, 2D echocardiography was normal (no RA, $\mathrm{RV}$ dilatation or hypokinesia or tricuspid regurgitation) and no evidence of Deep Venous Thrombosis (DVT) was there on compression Ultrasound. We suspected significant pulmonary micro-thrombosis and administered systemic tissue 
plasminogen activator (tPA). All cases had rapid improvement in oxygenation and dyspnoea (Fig. 1). All three patients were on room air by 3-7 days of tPA infusion. All three patients were discharged within 2 weeks after negative COVID19 PCR reports.

\section{Case 1}

Forty five years old male with uncontrolled diabetes was diagnosed COVID19 and he had $\mathrm{sPO}_{2}$ of $92 \%$ on admission. He was started on therapeutic doses of Low molecular weight heparin (LMWH). After 2 days of admission, he suddenly became breathless and his $\mathrm{FiO}_{2}$ overnight increased from 0.21 to 0.7 on Non-Invasive Ventilation (NIV). His Respiratory Rate (RR) was 40-45/min and patient became irritable due to worsening dyspnoea. 2D echocardiography and compression USG of legs was normal. D dimer was $1350 \mathrm{ng} / \mathrm{ml}$ and fibrinogen was $670 \mathrm{mg} / \mathrm{dl}$. He was started on tPA at $2 \mathrm{mg} / \mathrm{h}$ and he was given $30 \mathrm{mg}$ over $15 \mathrm{~h}$ along with Unfractionated Heparin (UFH) @ 500 U/h. After that his heparin was increased to $1000 \mathrm{IU} / \mathrm{h}$ and target was set to achieve aPTT of 80-90 s. Reason for shifting from LMWH to UFH was to have better control over bleeding episodes. After tPA was transfused, his RR decreased to $25-28 / \mathrm{min}$, $\mathrm{FiO}_{2}$ decreased from 0.7 to 0.5 . Over a course of 3 days his $\mathrm{FiO}_{2}$ decreased to 0.35 and on 6th day, he was maintaining spO2 of $>95 \%$ on room air and he was discharged by 10 th day after negative COVID19 PCR report.

\section{Case 2}

Sixty year female k/c/o Coronary Artery Disease and hypertension was admitted with history of breathlessness, cough and vomiting for 4 days. On presentation, her room air $\mathrm{sP}_{2}$ was 52\%. D-dimer and fibrinogen were $1787 \mathrm{ng} / \mathrm{ml}$ and $704 \mathrm{mg} / \mathrm{dl}$ respectively. Her P/F ratio was 90 on NIV $\left(\mathrm{FiO}_{2}\right.$ was 0.75 ) after 1 day of ICU management and she was getting fatigued and intubation was imminent due to worsening dyspnoea. 2D echocardiography was normal. She was given $50 \mathrm{mg}$ tPA over $3 \mathrm{~h}$. After a gap of $3 \mathrm{~h}$ of stopping tPA, her heparin was started @ 1000 IU/h. Within few hours of starting tPA, her RR decreased from 45/min to 20/min and she was much comfortable. Her $\mathrm{FiO}_{2}$ remained stable at 0.6 for 2 days and then decreased to 0.40 on third day and 0.21 after
Fig. 1 Decrease in fraction of inspiratory oxygen requirement $\left(\mathrm{FiO}_{2}\right)$ and improvement in $\mathrm{PaO}_{2} / \mathrm{FiO}_{2}$ ratio of three patients post $\mathrm{PAA}$ infusion. ABG was not done beyond 4th, 5th and 6th day for Case no. 3, 1 and 2 respectively
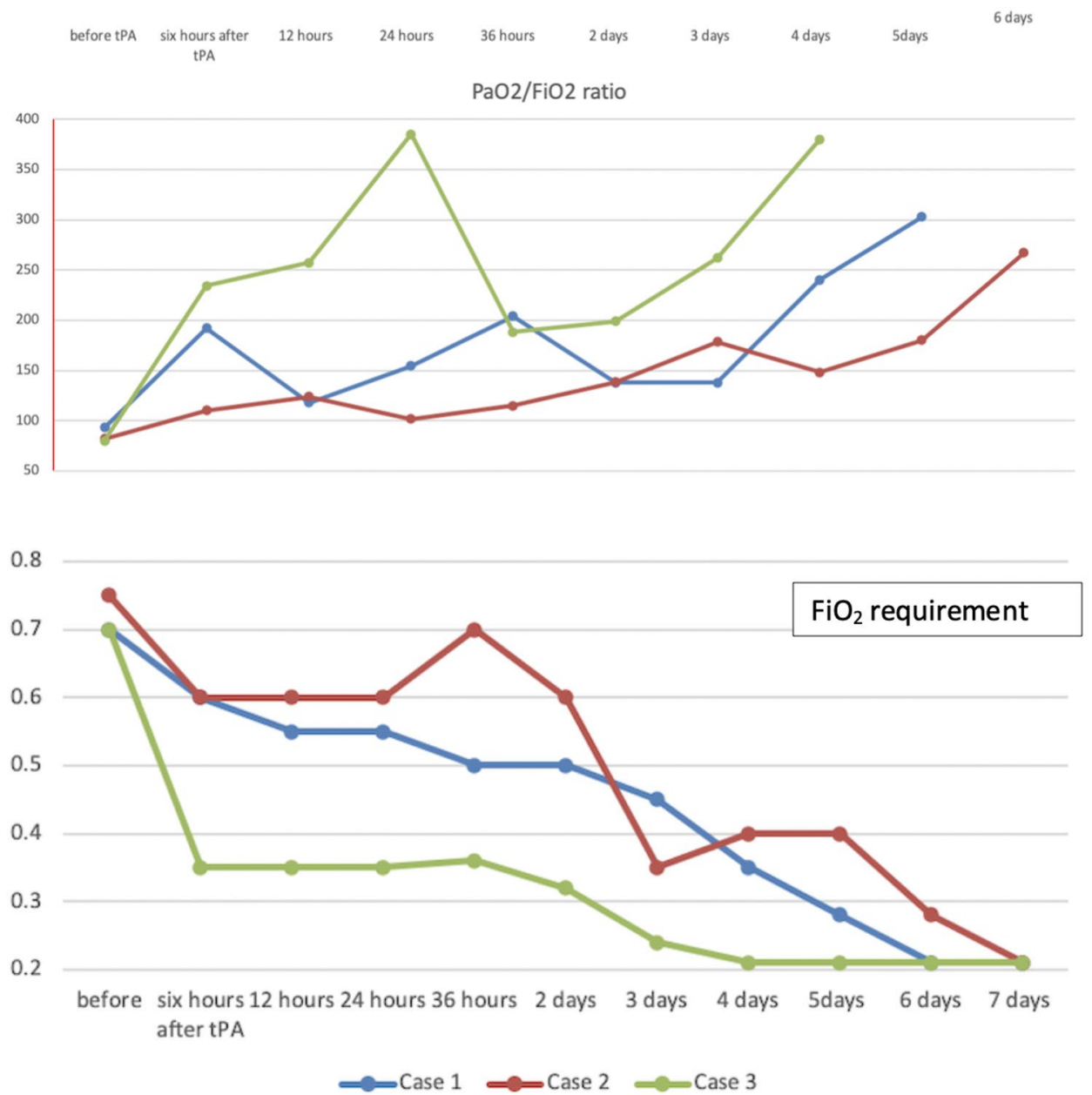
7 days of tPA infusion and she was discharged by 13th day after negative COVID19 PCR report.

\section{Case 3}

Fifty nine year obese hypothyroid female without any other comorbidities presented with breathlessness, fever and decreased appetite for 2 days. Her $\mathrm{SPO}_{2}$ was $58 \%$ on room air. Her P/F ratio was 80 with $\mathrm{FiO}_{2}$ of 0.7 on High Flow Nasal Canula (HFNC) after 1 day of ICU management. 2D echocardiography was normal and no evidence of DVT was there. D-dimer and fibrinogen were $4583 \mathrm{ng} / \mathrm{ml}$ and $415 \mathrm{mg} /$ dl respectively. As she was deteriorating rapidly, she was fast approaching stage where we had to intubate her. She was given $50 \mathrm{mg}$ tPA over $3 \mathrm{~h}$. After a gap of $3 \mathrm{~h}$, UFH was started @ 1000 IU/h. Within 2 h of starting tPA, her RR decreased from $40 / \mathrm{min}$ to $20 / \mathrm{min}$. $\mathrm{FiO}_{2}$ decreased drastically from 0.7 to 0.35 within $3 \mathrm{~h}$ of completion of tPA (Fig. 1). She was on room air after 3 day of tPA infusion and she got discharged by 8 th day after negative COVID19 PCR report.

\section{Discussion}

Consistent findings from few autopsies series have shown significantly high incidence of pulmonary embolism and thrombotic phenomenon in patients dying due to COVID19 [3-5]. These series have shown presence of fibrin rich microthrombi and macrothrombi developing in lungs of critically ill COVID19 patients. Probably COVID Induced Coagulopathy (CIC) mimics presentation of subclinical pulmonary thromboembolism: both disease have significant pulmonary vascular shunting without hypotension initially, with significantly raised markers like D-dimer and BNP. But unlike sub-massive PE (in which there is a welldefined clot), there is widespread microthrombi and continuous ongoing inflammation causing hypercoagulability in COVID19. In sub-massive PTE, mortality is in the range of $3-5 \%$, so thrombolysis is not advised routinely due to risk of thrombolysis induced life threatening bleeding (1\%). But in COVID19 which can cause severe hypercoagulable state in some patients, mortality rates varies from 30 to $50 \%$ in critically ill patients on HFNC to $80-90 \%$ in patients on mechanical ventilation [6]. Surprisingly, very few cases of bleeding have been reported with COVID; probably coagulation pathway is significantly tilted towards hypercoagulable state rather than bleeding tendency. One study showed complete fibrinolysis shutdown, as evidenced by elevated D-Dimer and complete failure of clot lysis at $30 \mathrm{~min}$ on thromboelastography in critically ill patients with COVID19 [7].

Two case series have used thrombolysis with tPA in COVID19 related ARDS who were on mechanical ventilation and were in deteriorating with varying success $[8,9]$. Out of seven patients in these two series: two patients expired, $\mathrm{paO} 2$ improvement occurred in four patients and inotropes dose was decreased in one patient.

After learning from the autopsy findings, we changed practice at our institute and we started giving therapeutic anticoagulation (in addition to methylprednisolone and pantoprazole) to all critically ill COVID19 patients presenting in ICU as a standard protocol. Even on therapeutic anticoagulation, some patients continue to deteriorate. So, we extrapolated low dose and ultralow dose used in MOPETT trial and The Ultra-slow PROMETEE Trial, where tPA doses of $50 \mathrm{mg}$ and $25 \mathrm{mg}$ were used for sub massive PE and prosthetic valve thrombosis respectively $[10,11]$. In both the trials, efficacy was similar to conventional high dose tPA with significant low fatal bleeding rates (nil and $0.8 \%$ in MOPETT and PROMOTEE trial respectively).

Our first case was deteriorating rapidly; was getting fatigued and agitated; he had a respiratory rate of $45 / \mathrm{min}$ and intubation was imminent. So decision to thrombolyse (with $30 \mathrm{mg}$ tPA over $15 \mathrm{~h}$ ) was taken on compassionate basis after interdisciplinary discussion. With the significant improvement in first case, we used tPA (50 mg over $3 \mathrm{~h}$ ) in next two patients who were rapidly deteriorating. Third case had the highest d-Dimer level $(4583 \mathrm{ng} / \mathrm{ml})$ and she had the fastest response to tPA (Fig. 1).

Low dose UFH (500 U/h) was transfused along with tPA in first case. Anticoagulation (I.V. UFH) was suspended during thrombolysis in second and third case and was restarted after $3 \mathrm{~h}$ of completion of tPA with target aPTT of 70-90 s. With an intense hyperinflammation continuing in COVID19, we believe therapeutic anticoagulation should not be stopped for too long. So that's why we shifted to a shorter duration $(3 \mathrm{~h})$ of tPA after our first case. Patients were shifted from UFH to Enoxaparin twice a day once patient was stabilised.

These three patients had significantly early improvement compared to other patients earlier admitted with COVID19 in our ICU with similar severe condition. In our experience, avoiding intubation is the best strategy since survival results are very poor in intubated COVID19 patients [6]. So thrombolysing might be an attractive alternative in carefully selected individuals with rapidly deteriorating respiratory failure, as it may avoid intubation. Importantly, the decision of thrombolysis was always taken in consultation in interdisciplinary team after ruling out any other cause of hypoxemia. We could not get C.T. Pulmonary Angiography of these patients before thrombolysis due to poor general condition; although there was no evidence of PTE on echocardiography or of DVT on compression USG. So there was no conventional indication of thrombolysis (like cardiogenic shock or RV dilatation) in these patients, yet after thrombolysis, we saw dramatic changes in oxygenation of all patients. 
We are of the opinion that tPA $50 \mathrm{mg}$ (over $3 \mathrm{~h}$ ) can be given in critically ill COVID19 patients who fulfil following all five criteria:

1. Rapidly rising $\mathrm{FiO}_{2}$ requirement $\geq 0.7$ (on $\mathrm{HFNC}$ or NIV)

2. $\mathrm{P} / \mathrm{F}$ ratio of $<100$

3. D dimer $>1000 \mathrm{ng} / \mathrm{ml}$

4. No absolute contraindications of thrombolysis

5. No other cause of deterioration like secondary infection, fluid overload.

Traditionally considered "high risk" fibrinolytic agents have a major bleeding risk of $1-3 \%$ and $<1 \%$ chances of fatal bleed [10-12]. This is significantly less than mortality rates of $50-88 \%$ seen in critically ill COVID19 patients on ventilatory support [6]. We did not encounter any bleeding episode in any of our cases.

In this unprecedented pandemic with high mortality rates, thrombolysis is a relatively safe and effective option in carefully selected critically ill patients of COVID19. However usefulness of fibrinolytic agents in management will be more clear, once results of randomised trial of tPA will be available [13].

Author contributions Concept : AG, SS, JS. Manuscript preparation: AG, SS, YN, PS.

Funding No funding was required for this paper.

\section{Compliance with ethical standards}

Conflict of interest The authors declare that they have no conflict of interest.

\section{References}

1. McGonagle D, O’Donnell JS, Sharif K, Emery P, Bridgewood C (2020) Immune mechanisms of pulmonary intravascular coagulopathy in COVID-19 pneumonia. Lancet Rheumatol. https://www.thelancet.com/journals/lanrhe/article/PIIS26659913(20)30121-1/abstract

2. Paranjpe I, Fuster V, Lala A, Russak A, Glicksberg BS, Levin MA, et al (2020) Association of treatment dose anticoagulation with in-hospital survival among hospitalized patients with
COVID-19. J Am Coll Cardiol. http://www.onlinejacc.org/conte nt/early/2020/05/05/j.jacc.2020.05.001

3. Wichmann D, Obbelode F, Vogel H, Hoepker WW, Nierhaus A, Braune $S$ et al (2012) Virtual autopsy as an alternative to traditional medical autopsy in the intensive care unit: a prospective cohort study. Ann Intern Med 156(2):123

4. Carsana L, Sonzogni A, Nasr A, Rossi R, Pellegrinelli A, Zerbi $\mathrm{P}$, et al. (2020) Pulmonary post-mortem findings in a large series of COVID-19 cases from Northern Italy. Infect Dis. http://medrx iv.org/lookup/doi/10.1101/2020.04.19.20054262

5. Lax SF, Skok K, Zechner P, Kessler HH, Kaufmann N, Koelblinger $\mathrm{C}$ et al (2020) Pulmonary arterial thrombosis in COVID19 with fatal outcome: results from a prospective, single-center, clinicopathologic case series. Ann Intern Med. https://www.acpjo urnals.org/doi/10.7326/M20-2566

6. Presenting characteristics, comorbidities, and outcomes among 5700 patients hospitalized with COVID-19 in the New York City Area | Critical care medicine I JAMA | JAMA Network [Internet]. [cited 2020 May 28]. https://jamanetwork.com/journals/jama/fulla rticle/2765184

7. Wright FL, Vogler TO, Moore EE, Moore HB, Wohlauer MV, Urban S et al (2020) Fibrinolysis shutdown correlates to thromboembolic events in severe COVID-19 infection. J Am Coll Surg. https://doi.org/10.1016/j.jamcollsurg.2020.05.007.

8. Poor HD, Ventetuolo CE, Tolbert T, Chun G, Serrao G, Zeidman A et al (2020) COVID-19 critical illness pathophysiology driven by diffuse pulmonary thrombi and pulmonary endothelial dysfunction responsive to thrombolysis. medRxiv. https://doi. org/10.1101/2020.04.17.20057125

9. Wang J, Hajizadeh N, Moore EE, McIntyre RC, Moore PK, Veress LA et al (2020) Tissue plasminogen activator (tPA) treatment for COVID-19 associated acute respiratory distress syndrome (ARDS): A case series. J Thromb Haemost. https://onlinelibrary. wiley.com/doi/abs/10.1111/jth.14828

10. Sharifi M, Bay C, Skrocki L, Rahimi F, Mehdipour M, MOPETT Investigators (2013) Moderate pulmonary embolism treated with thrombolysis (from the "MOPETT" trial). Am J Cardiol 111(2):273-277

11. Özkan M, Gündüz S, Gürsoy OM, Karakoyun S, Astarcığlu MA, Kalçık M et al (2015) Ultraslow thrombolytic therapy: a novel strategy in the management of PROsthetic MEchanical valve thrombosis and the prEdictors of outcomE: the ultra-slow PROMETEE trial. Am Heart J 170(2):409-418

12. Wang C, Zhai Z, Yang Y, Wu Q, Cheng Z, Liang L et al (2010) Efficacy and safety of low dose recombinant tissue-type plasminogen activator for the treatment of acute pulmonary thromboembolism. Chest 137(2):254-262

13. Fibrinolytic therapy to treat ARDS in the setting of COVID-19 infection-Full text view. ClinicalTrials.gov. [cited 2020 May 26]. https://clinicaltrials.gov/ct2/show/NCT04357730

Publisher's Note Springer Nature remains neutral with regard to jurisdictional claims in published maps and institutional affiliations. 